\title{
TRIPHASIC TIME COURSE OF INOTROPIC EFFECT MEDIATED BY $\alpha$-ADRENOCEPTORS IN THE LEFT ATRIA OF GUINEA PIGS
}

\author{
Yuichi HATTORI and Morio KANNO \\ 2nd Department of Pharmacology. Hokkaido University School of Medicine. Sapporo 060. Japan
}

Accepted March 6, 1981

\begin{abstract}
The time course of the inotropic effects of phenylephrine in the presence of sotalol was investigated in the electrically driven left atria of guinea pigs. Phenylephrine at a concentration of $10^{-5} \mathrm{M}$ in the presence of sotalol $\left(5 \times 10^{-5} \mathrm{M}\right)$ produced triphasic time response curves which composed of an initial positive inotropic phase followed by a negative inotropic phase and then a second positive inotropic phase, at a rate of 0.2 $\mathrm{Hz}$, whereas isoproterenol $\left(10^{-8} \mathrm{M}\right)$ induced a monophasic time course of the positive inotropic effect. Phenoxybenzamine $\left(10^{-6} \mathrm{M}\right)$ or phentolamine $\left(6 \times 10^{-6} \mathrm{M}\right)$ depressed the inotropic effects induced by phenylephrine in the presence of sotalol and abolished the triphasic pattern of the time response curves. The negative inotropic effect leading to the occurrence of the triphasic time course was concentration and frequency dependent, i.e. it became more manifest with increase in the concentration of phenylephrine and with decrease in the stimulation frequency. At an extremely low frequency ( 1 beat/min), however, phenylephrine produced an insignificant increase in the contractile force and the characteristic triphasic pattern did not appear. These results indicate that stimulation of $\alpha$-adrenoceptors produces a frequency-dependent negative inotropic and positive inotropic effect in the left atria of guinea pigs.
\end{abstract}

Since Wenzel and Su (1) suggested the presence of $\alpha$-adrenoceptors in the ventricular muscles of rats, many studies have provided pharmacological evidence for the existence of $\alpha$-adrenoceptors which mediate the positive inotropic effect (PIE) in the isolated cardiac preparations of various mammalian species (2-5). Recently, binding studies using a radioligand, $\left[{ }^{3} \mathrm{H}\right]$-dihydroergocryptine, have identified the sites possessing the characteristics of $\alpha$-adrenoceptors in the membrane fraction of the rat and rabbit myocardium $(6,7)$.

Comparative studies of $\alpha$ - and $\beta$-adrenoceptor mediated PIE have elucidated the differences between these receptors. The most prominent difference is that PIE produced by stimulation of $\alpha$-adrenoceptors is not accompanied by an increase in myocardial cyclic AMP content (8-11).

Osnes et al. (12) observed that the time response curves of the contractile force after $\alpha$-adrenoceptor stimulation in the rat myocardium showed a triphasic pattern which differed from the monophasically increasing pattern after $\beta$-adrenoceptor stimulation. Furthermore, the triphasic time response curves obtained in the rat cardiac tissues were distinctly different from the monophasic ones of the $\alpha$-mimetic PIE observed in the rabbit papillary muscles $(10,11)$, the left atria of cats (5) and the guinea pig ventricular 
muscles (5). Osnes et al. (12) suggested the presence of $\alpha$-adrenoceptors which would exert an inhibitory action in the rat myocardium, which was in agreement with that of Wenzel and Su (1).

The preliminary finding that the time response curves of the contractile force after $\alpha$-adrenoceptor stimulation also became triphasic in the left atria of guinea pigs as they did in the rat myocardium (12) prompted us to investigate in detail the time course of the inotropic effects mediated by $\alpha$-adrenoceptors in this preparation, with the aim of clarifying the influence of stimulation frequency on the triphasic development of the inotropic effect. We were particularly interested in this subject because of the well known frequencydependency of PIE mediated by $\alpha$ adrenoceptors in other cardiac preparations (13-15).

Our findings indicate that stimulation of $\alpha$-adrenoceptors produces a depressive effect along with PIE, thus forming the triphasic time response curves in the left atria of guinea pigs, and that this depressive effect is dependent on the concentration of the agonist and the stimulation frequency.

\section{MATERIALS AND METHODS}

Guinea pigs of either sex weighing 410 to $780 \mathrm{~g}$ were killed by a blow on the head, and the hearts quickly removed and transferred to a dissection bath filled with KrebsHenseleit solution at room temperature. The left atria were dissected free and then mounted in an organ bath containing $50 \mathrm{ml}$ of KrebsHenseleit solution of the following composition (mM): $\mathrm{NaCl} 119, \mathrm{CaCl}_{2} 2.5, \mathrm{KCl}$ 4.8, $\mathrm{MgSO}_{4}$ 1.2, $\mathrm{KH}_{2} \mathrm{PO}_{4}$ 1.2, $\mathrm{NaHCO}_{3}$ 24.9, glucose 10.0, ascorbic acid 0.054 . The bath was continuously bubbled with $95 \% \quad \mathrm{O}_{2}$ and $5 \% \quad \mathrm{CO}_{2}$ and the temperature was maintained at $30 \pm 1^{\circ} \mathrm{C}$.

After one end of the atria was fixed on needle-shaped stimulating electrodes, the organ was driven electrically at constant rates with rectangular pulses of $1 \mathrm{msec}$ duration and an intensity of twice the diastolic threshold, which were delivered by an electronic stimulator (Sanei-Sokki 3F46) through an isolation unit (Sanei-Sokki 5361). The isometric tension was registered with a transducer (Sanei-Sokki 45196) on a penrecorder (Nihon Kohden RJG-3026) through a preamplifier (Nihon Kohden RP-5). The resting tension loaded on the preparations was adjusted to $2 \mathrm{~g}$.

After a 40 to 60 min period of equilibration at a stimulation frequency of $1 \mathrm{~Hz}$, the experiments were started at a frequency of $0.2 \mathrm{~Hz}$ unless stated otherwise, and the frequency was then changed as required. Isoproterenol and phenylephrine were administered after the steady-state contractions were obtained at each frequency. Antagonists were added $60 \mathrm{~min}$ before the administration of the agonists.

In some experiments, catecholaminedepleted atria were used. Reserpine $(5 \mathrm{mg} /$ $\mathrm{kg}$, i.p.) was given to the animals $24 \mathrm{hr}$ prior to the experiments; this dose of reserpine reportedly depletes almost completely the norepinephrine content $(>95 \%)$ in the left atria (16).

The results were expressed in mean \pm S.E. with the number of experiments.

The following drugs were used: I-phenylephrine hydrochloride (Sigma), d,I-isoproterenol hydrochloride (Sigma), sotalol hydrochloride (Bristol), phenoxybenzamine hydrochloride (Smith-Kline and French), phentolamine hydrochloride (CIBA-Geigy) and reserpine (Tokyo Kasei).

Statistical significance of differences was determined by Student's t-test.

\section{RESULTS}

1. Time course of the inotropic changes induced by phenylephrine: In the presence of sotalol $\left(5 \times 10^{-5} \mathrm{M}\right)$, which antagonized 


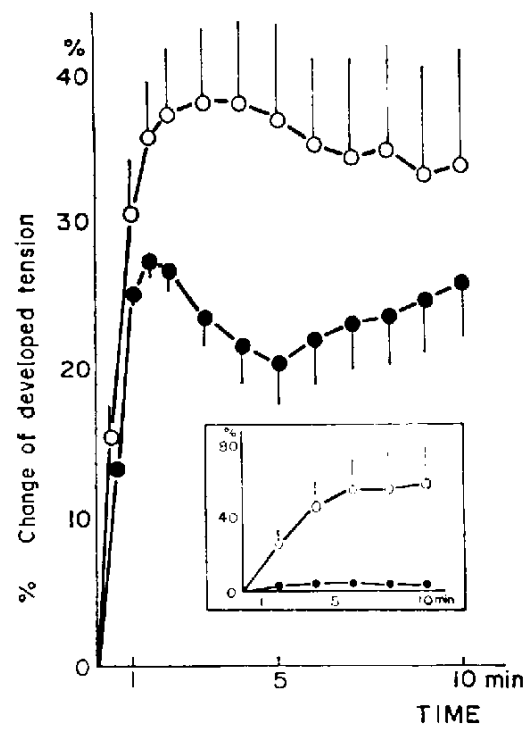

Fig. 1. Time course of the positive inotropic effect produced by $10^{-5} \mathrm{M}$ phenylephrine (Phe) in the left atria of guinea pigs stimulated at $0.2 \mathrm{~Hz}$. Ordinates: change of the developed tension in percents of the values before the addition of agonist. Abscissa: time after addition of agonist.

- in the presence of $5 \times 10^{-5} \mathrm{M}$ sotalol: $\mathrm{O}-\mathrm{O}$ : in the absence of sotalol. Effect of $10^{-8} \mathrm{M}$ isoproterenol is shown in the inset. Number of experiments: isoproterenol. $N=6$. Phe, $N=8$. The means $\pm S$.E. are given. almost completely the positive inotropic effect (PIE) produced by $10^{-8} \mathrm{M}$ of isoproterenol (Fig. 1, Inset), phenylephrine (Phe) at a concentration of $10^{-5} \mathrm{M}$ produced the inotropic changes which indicated a complicated time course in the left atria of guinea pigs electrically driven at a rate of $0.2 \mathrm{~Hz}$ (Fig. 1). The triphasic pattern of the time response curves, characterized by an initial increasing phase followed by a declining phase and then a second increasing phase differed from the monophasic time course of PIE induced by Phe in the absence of sotalol and that by isoproterenol (Fig. 1). A typical example is depicted in Fig. 2. The triphasic time course of the inotropic changes disappeared after further treatment with phenoxybenzamine (Fig. 2C).

The triphasic pattern in the time response curves was observed at concentrations of Phe above $10^{-5} \mathrm{M}$ (Fig. 3). At $10^{-7} \mathrm{M}$ the increased tension quickly reached its maximum and then remained at this level. With an increase in the concentrations to $10^{-6} \mathrm{M}$, an initial increase in tension, significantly larger than that at $10^{-7} \mathrm{M}$, was

A.

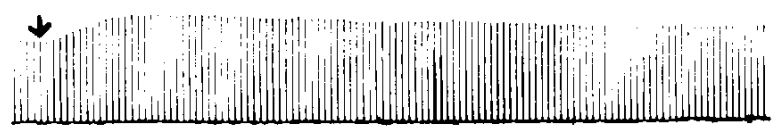

8.

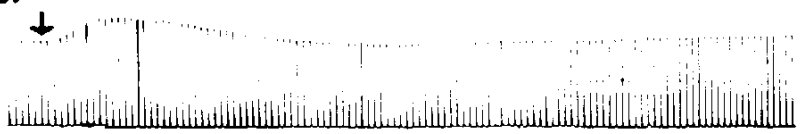

C.

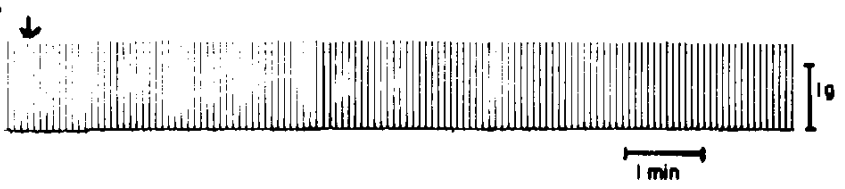

Fig. 2. Inotropic effect of $10^{-5} \mathrm{M}$ phenylephrine (Phe) in the left atria of guinea pigs.

(A) in the absence of adrenolytic drugs. (B) in the presence of $5 \times 10^{-5} \mathrm{M}$ sotalol.

(C) in the presence of $5 \times 10^{-5} \mathrm{M}$ sotalol and $10^{-6} \mathrm{M}$ phenoxybenzamine. The left atria were stimulated at a frequency of $0.2 \mathrm{~Hz}$. Arrow indicates administration of Phe. 


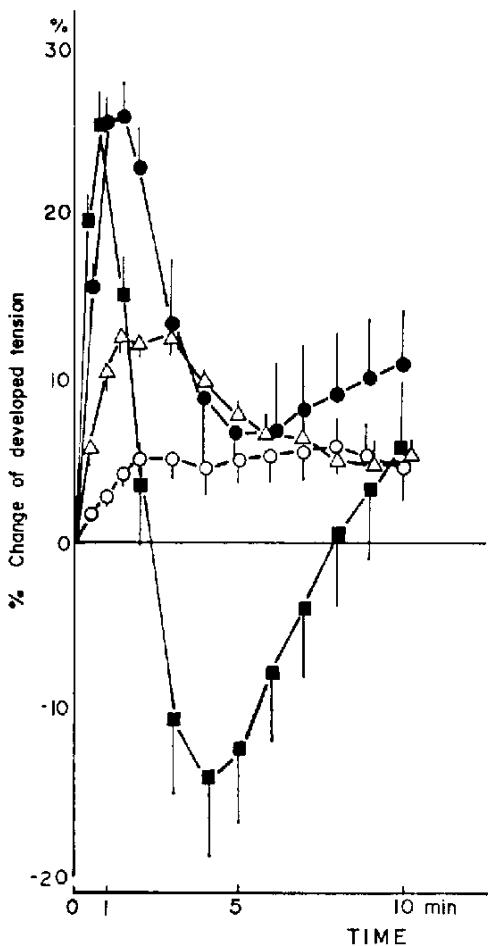

Fig. 3. Time course of the inotropic effects of various concentrations of phenylephrine (Phe) in the presence of $5 \times 10^{-5} \mathrm{M}$ sotalol in the left atria of guinea pigs stimulated at $0.2 \mathrm{~Hz}$. Ordinates and abscissa are the same as in Fig. 1. $O-O: 10^{-7} \mathrm{M}: \triangle \longrightarrow \triangle: 10^{-6} \mathrm{M}$ : $10^{-5} \mathrm{M}: \square: 10^{-4} \mathrm{M}$ Phe. The means $\pm S$. E. of six experiments are given.

followed by a gradual decline which was not accompanied by the second increasing phase. The triphasic pattern of the time response curves observed at $10^{-5} \mathrm{M}$ became more manifest at $10^{-4} \mathrm{M}$. At this concentration. the contractile force which increased quickly and attained its maximum shortly after the administration of Phe declined in the succeeding several minutes to a level below that of the control $(-14.4 \% \pm 4.8, n=6, p<0.05)$ and then once again increased gradually $(+5.7 \% \pm 4.2$ at $10 \mathrm{~min}, \mathrm{n}=6)$.

At a concentration of $10^{-6} \mathrm{M}$ phenoxybenzamine abolished both of the positive and negative inotropic phases induced by $10^{-5} \mathrm{M}$ and $10^{-4} \mathrm{M}$ Phe in the presence of sotalol, as shown in Fig. 4A and $B$. Pretreatment of $10^{-8} \mathrm{M}$ phenoxybenzamine attenuated the declining phase following the initial positive inotropic phase without affecting the latter significantly and altered the pattern of the time response curves of $10^{-4}$ and $10^{-5} \mathrm{M}$ Phe to those which were produced by Phe of one order less concentration in the absence of $\alpha$-adrenoceptor antagonists, respectively (Fig. $4 A$ and $B$ ). Upon the administration of $3 \times 10^{-6} \mathrm{M}$ phentolamine, a similar alteration in the pattern of the time response curves was also observed (Fig. $4 C$ and D). The time response curves of $10^{-5} \mathrm{M}$ Phe lost its characteristic triphasic pattern and became biphasic, as was observed with $10^{-6} \mathrm{M}$ Phe (Fig. 4C). However, the initial positive inotropic response remained unchanged. Increase in the concentration of phentolamine to $6 \times 10^{-6} \mathrm{M}$ reduced a positive inotropic effect. The positive inotropic response of $10^{-4} \mathrm{M}$ Phe was potentiated and the negative inotropic phase was markedly attenuated in the presence of $3 \times 10^{-6} \mathrm{M}$ phentolamine (Fig. 4D). As a whole, the altered pattern of the time response curves became qualitatively similar to those of $10^{-5} \mathrm{M}$ Phe.

In the catecholamine-depleted left atria obtained from the reserpinized animals, the triphasic pattern of the time response curves induced by Phe at $10^{-4}$ and $10^{-5} \mathrm{M}$ in the presence of sotalol did not differ qualitatively from that observed in the normal preparations, and the antagonizing effect of phenoxybenzamine was apparent (Fig. 5).

2. Influence of the stimulation frequency on the triphasic time course: The characteristic triphasic pattern of the time response curves of Phe observed at a stimulation rate of $0.2 \mathrm{~Hz}$ became obscure when the stimulation rate was increased (Fig. 6). To show more clearly the frequency dependency of the triphasic pattern of the inotropic effects, the ratio of the tension observed at the bottom of the second declining phase to the 
a.
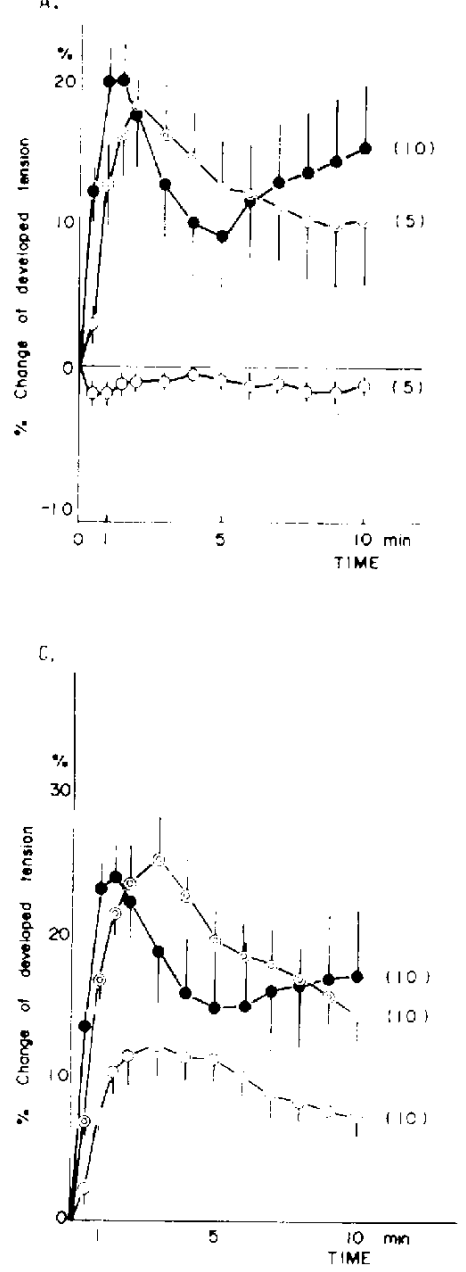

B.
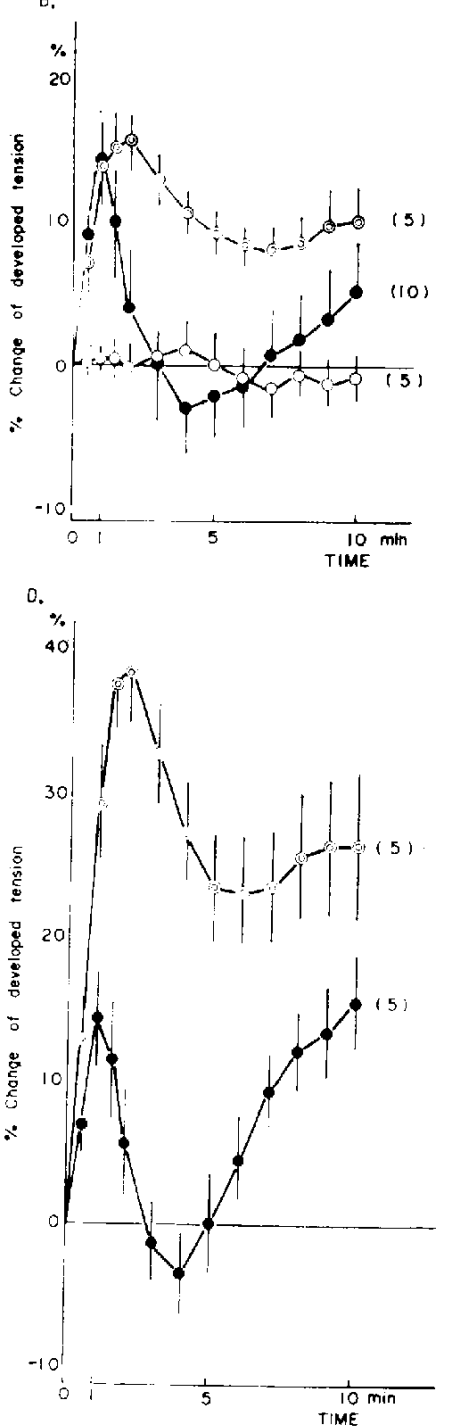

Fig. 4. Influence of phenoxybenzamine (A, B) and phentolamine (C, D) on the time course of the inotropic effects of phenylephrine (Phe) in the presence of $5 \times 10^{-5} \mathrm{M}$ sotalol in the left atria of guinea pigs stimulated at $0.2 \mathrm{~Hz}$. Ordinates and abscissa are the same as in Fig. 1. The concentrations of Phe are $10^{-5} \mathrm{M}$ and $10^{-4} \mathrm{M}$ in $\mathrm{A}, \mathrm{C}$ and $\mathrm{B}, \mathrm{D}$, respectively. - Phe; $O$ - (O): Phe $+10^{-8} \mathrm{M}$ phenoxybenzamine $\left(\mathrm{A} . \mathrm{B}\right.$ ) or $3 \times 10^{-6} \mathrm{M}$ phentolamine $(C, D): O-O$ : Phe $+10^{-6} \mathrm{M}$ phenoxybenzamine $(A, B)$ or $6 \times 10^{-6} \mathrm{M}$ phentolamine (C). $\alpha$-adrenoceptor blocking agents were administered $60 \mathrm{~min}$ before addition of Phe. Number of observations is shown in parentheses. The means \pm S.E. are given.

maximally increased tension in the initial positive inotropic phase was plotted against the stimulation rate (Fig. 7). In this presentation. $100 \%$ means no decline in the contractile force after it reached its maximum.
The ratios obtained at $10^{-4} \mathrm{M}$ of Phe were less than those at $10^{-5} \mathrm{M}$ at any stimulation frequency, and the ratios at both concentrations of Phe increased with increments of the stimulation frequency. 


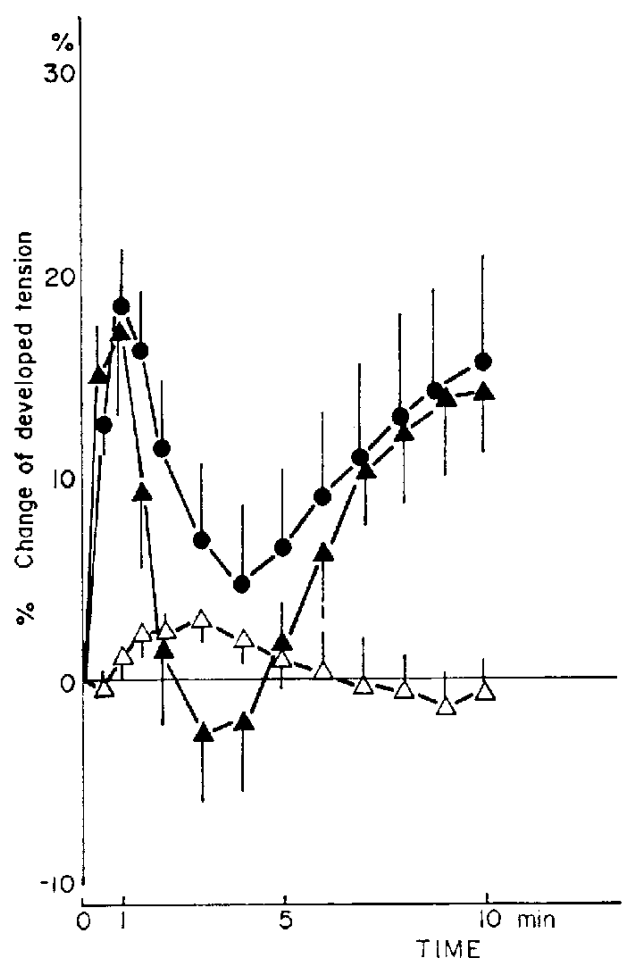

Fig. 5. Time course of the inotropic efrects of phenylephrine (Phe) in the presence of $5 \times 10^{-5}$ $M$ sotalol in the left atria of reserpinized guinea pigs stimulated at $0.2 \mathrm{~Hz}$. Ordinates and abscissa are the same as in Fig. 1.

$10^{-5} \mathrm{M}$ Phe: $\mathbf{A}-\mathbf{\Delta}: 10^{-4} \mathrm{M}$ Phe: $\triangle-\triangle \Delta$ : $10^{-4} \mathrm{M}$ Phe $+10^{-6} \mathrm{M}$ phenoxybenzamine. The animals were given reserpine (5 $\mathrm{mg} / \mathrm{kg}$ i.p.) $24 \mathrm{hr}$ before the experiments. The means \pm S.E. of six experiments are given.

At an extremely low stimulation rate of 1 beat $/ \mathrm{min}$. Phe at $5 \times 10^{-5} \mathrm{M}$ produced monophasic PIE in the presence of sotalol $(+8.6 \% \pm 3.4, n=5)$ without evidence of the triphasic pattern.

\section{DISCUSSION}

Although it is generally accepted that $c k$ adrenoceptor stimulation produces the positive inotropic effect (PIE) in various isolated cardiac preparations, the underlying mechanism of this phenomenon remains unclear, except for the suggestion that it is different from that involved in PIE mediated

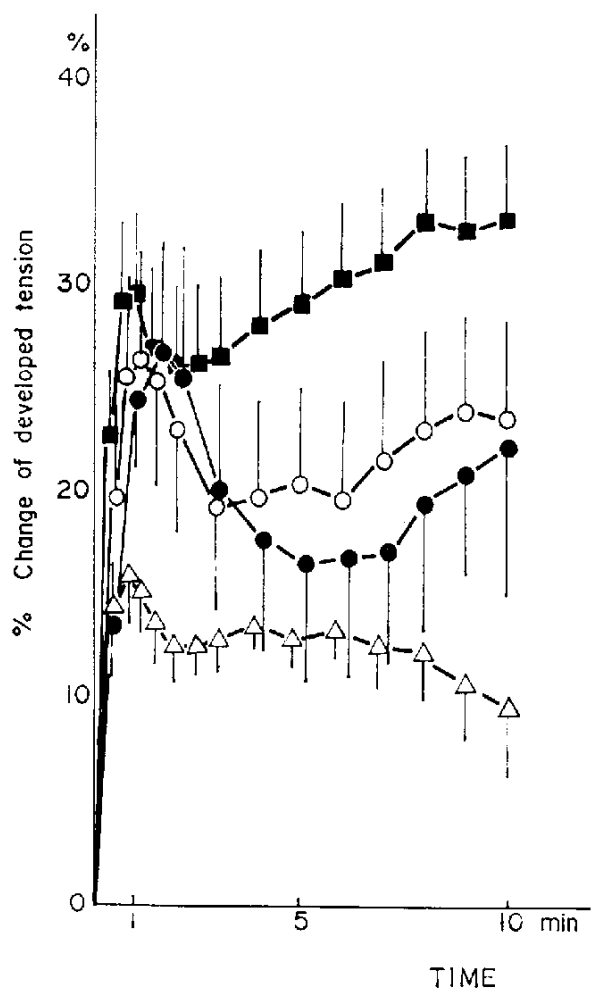

Fig. 6. Time course of the inotropic effects of $10^{-5} \mathrm{M}$ phenylephrine in the presence of $5 \times 10^{-5}$ $M$ sotalol in the left atria of guinea pigs stimulated at different frequencies. Ordinates and abscissa are the same as in Fig. 1. $0.2 \mathrm{~Hz} ; 0-0: 0.5 \mathrm{~Hz}: \square-\square: 1 \mathrm{~Hz}$; $\triangle-\triangle: 2 \mathrm{~Hz}$. The means \pm S.E. of seven experiments are given.

by $\beta$-adrenoceptors $(8-15,17,18)$.

The existence of $\alpha$-adrenoceptors which mediate PIE in the left atria of guinea pigs was substantiated by Govier (2, 3) and Wagner and Brodde (5). However, the present study revealed that in these preparations, the PIE induced by phenylephrine (Phe) in the presence of sotalol showed a triphasic time course consisting of an initial increasing phase followed by a declining phase and then a second increasing phase. This complex time course was distinguishable from the rather simple, monophasic increase in the contractile force produced by stimulation of $\beta$-adrenoceptors. The declining 


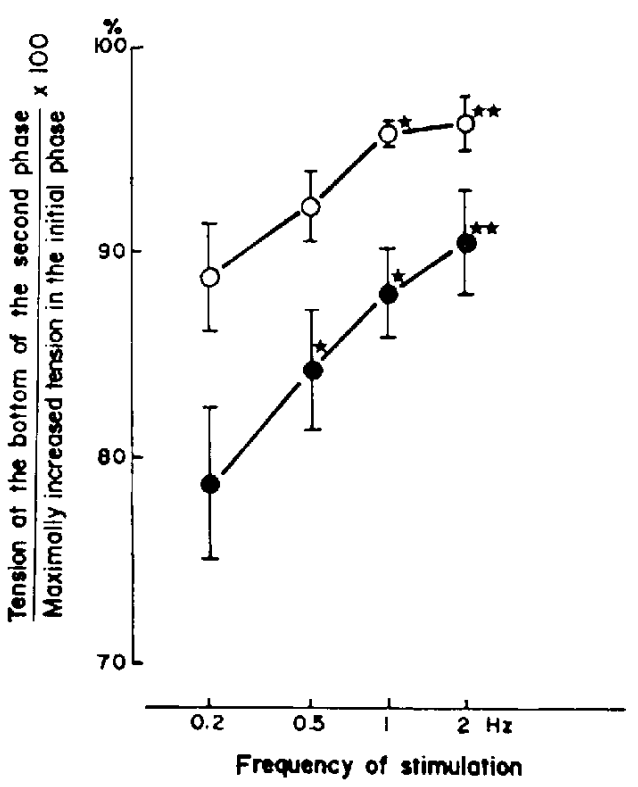

Fig. 7. Frequency-dependency of the depressive effect induced by phenylophrine (Phe) in the presence of $5 \times 10^{-5} \mathrm{M}$ sotalol in the left atria of guinea pigs. Ordinates: a ratio of the tension at the bottom of the second declining phase to the maximally increased tension in the initial positive inotropic phase. $100 \%$ means no decline in the contractile force after attainmert of the maximal level. Abscissa: frequency of stimulation. $\mathrm{O}-\mathrm{O}: 10^{-5} \mathrm{M}$ Phe $(\mathrm{n}=7)$ : -.- $10^{-4} \mathrm{M}$ Phe $(n=7) .{ }^{*} P<0.05$. ${ }^{*} P<0.01$ v.s. values obtained by administration of Phe at $0.2 \mathrm{~Hz}$. The meantS.E. are given.

phase, which led to the manifestation of the triphasic pattern, was found to be dependent upon the concentration of the agonist and the stimulation frequency. At the highest concentration of Phe used in this study $\left(10^{-4} \mathrm{M}\right)$ and at the optimal stimulation rate for inducing the declining phase $(0.2 \mathrm{~Hz})$, the contractile force was significantly depressed to a level below the control tension at the bottom of a dip formed between the initial positive and the second positive inotropic phases, suggesting the active participation of a negative inotropic mechanism.
Involvement of $\alpha$-adrenoceptors in the negative inotropic mechanism is suggested by the fact that treatment with phenoxybenzamine $\left(10^{-8} \mathrm{M}\right)$ or phentolamine $\left(3 \times 10^{-6}\right.$ $M)$ reduced the negative inotropic phase elicited by $10^{-4} \mathrm{M}$ or $10^{-5} \mathrm{M}$ Phe and led to a bluntness of the characteristic triphasic pattern of the time response curves or to the alteration of the pattern to the biphasic one which characterizes the time response curves of $10^{-6} \mathrm{M}$ Phe. The observed alterations of the pattern in the presence of the $\alpha$ adrenoceptor antagonists were not accompanied by significant changes of the initial PIE except that of $10^{-4} \mathrm{M}$ Phe which was markedly potentiated in the presence of $3 \times 10^{-6} \mathrm{M}$ phentolamine. However, increase in the concentration of phenoxybenzamine to $10^{-6} \mathrm{M}$ abolished the PIE and resulted in disappearance of the triphasic pattern, and phentolamine $6 \times 10^{-6} \mathrm{M}$ significantly reduced the PIE with altering the pattern. Thus, the negative inotropic mechanism appears to be more susceptible to the $\alpha$-adrenoceptor antagonists than the PIE, and therefore the preferential block of the negative inotropic mechanism is assumed to produce the potentiated PIE. In fact, it was observed that phentolamine at a concentration of $3 \times 10^{-6} \mathrm{M}$ augmented the initial PIE of $10^{-4} \mathrm{M}$ Phe. Relating to this observation, it should be noted that the initial PIE which increased concentration-dependently up to $10^{-5} \mathrm{M}$ did not show a further increment or sometimes was reduced in accordance with the manifestation of the declining phase at the concentration of Phe. It is quite probable that the negative inotropic mechanism triggered by Phe would inhibit the proper development of PIE. Relative extent of the PIE and the negative one produced concurrently by stimulation of $\alpha$-adrenoceptors would determine the degree of the potentiation of the PIE by phentolamine. This accounts for the lack of the potentiated 
PIE of $10^{-5} \mathrm{M}$ Phe after the treatment of phentolamine. However, it could be seen that phentolamine induced a delay in time to the maximum PIE. The potentiated initial PIE was lacking with $10^{-8} \mathrm{M}$ phenoxybenzamine, nevertheless it altered the triphasic pattern of the time response curves of $10^{-4} \mathrm{M}$ Phe as did phentolamine. This may indicate that lower concentrations of phenoxybenzamine are required to antagonize preferentially the negative inotropic mechanism. There is another possibility that the antagonist may not have a differential influence on the PIE and on the negative one. We are now attempting to characterize the $\alpha$-adrenoceptor antagonists including prazosin and yohimbine from their concentration-dependent influence on the triphasic pattern of the time response curves of Phe.

Recently, $\alpha$-adrenoceptors present at the presynaptic nerve terminals and regulating the release of the neurochemical transmitters were differentiated from those at the postsynaptic membranes (19), Our finding that the qualitatively comparable triphasic time course was observed in the catecholaminedepleted atria supports the view that the characteristic pattern of the time response curves is mediated by the postsynaptic $\alpha$-adrenoceptors.

The depressive effect that establishes the second declining phase and leads to the manifestation of the triphasic pattern showed a concentration- and frequency-dependency: it became more prominent with decrease in the stimulation rate and with increase in the concentration of Phe. However, at an extremely low frequency of stimulation such as 1 beat/min, the PIE of Phe was slight and the characteristic triphasic pattern disappeared. Interestingly, the depressive component manifests itself in a range of stimulation frequency that is coincident with the optimal range for inducing PIE. It seems likely that a summation of the inotropic effects working in opposite directions would determine an actual trace of the time response curves of the contractile force after stimulation of $\alpha$-adrenoceptors.

A concomitant depression of the contractile force with PIE produced by stimulation of $\alpha$-adrenoceptors has been observed in the ventricular and atrial muscles of rats $(1,12)$ and in the papillary muscles of rabbits (13). The negative inotropic effect induced by methoxamine in the latter preparations. however, was not antagonised by phentolamine (13). Osnes et al. (9, 12) reported that in the rat myocardium, the depressive component resulting in the triphasic pattern of the time response curves of Phe was antagonized by $\alpha$-adrenoceptor antagonists, and suggested, in accordance with Wenzel and $\mathrm{Su}(1)$, that the rat myocardium possesses inhibitory $\alpha$-adrenoceptors as well as stimulatory $\alpha$-adrenoceptors.

Our findings are plausibly explainable if it is assumed that inhibitory $\alpha$-adrenoceptors are also present in the left atria of guinea pigs, as they are in the rat myocardium, and that their stimulation exerts a negative inotropic effect showing a time course different from the positive one. However, as yet we have no direct evidence which substantiates the presence of two functionally different subsets of $\alpha$-adrenoceptors. Alternatively, $\alpha$-adrenoceptors belonging to one population may trigger concurrently inhibitory as well as stimulatory influences on the transsarcolemmal and intracellular $\mathrm{Ca}^{++}$ movements regulating the beat-to-beat tension.

\section{REFERENCES}

1) Wenzel, D.G. and Su, J.L.: Interactions between sympathomimetic amines and blocking agents on the rat ventricular strip. Archs int. Pharmacodyn. Thér. 160, 379-389 (1966)

2) Govier, W.C.: A positive inotropic effect of phenylephrine mediated through alpha adrenergic receptors. Life Sci. 6, 1361-1365 
(1967)

3) Govier, W.C.: Myocardial alpha adrenergic receptors and their role in the production of a positive inotropic effect by sympathomimetic agents. J. Pharmacol. exp. Ther. 159, 82-90 (1968)

4) Schümann, H.J., Endoh, M. and Wagner, J.: Positive inotropic effects of phenylephrine in the isolated rabbit papillary muscle mediated both by $\alpha$ - and $\beta$-adrenoceptors. NaunynSchmiedeberg's Arch. Pharmacol. 284, 133-148 (1974)

5) Wagner, J. and Brodde, O.E.: On the presence and distribution of $\alpha$-adrenoceptors in the heart of various mammalian species. NaunynSchmiedeberg's Arch. Pharmacol. 302, 239254 (1978)

6) Williams, R.S. and Lefkowitz, D.J.: Alphaadrenergic receptors in rat myocardium. Identification by binding of $\left[{ }^{3} \mathrm{H}\right]$ dihydroergocryptine. Circulation Res. 43, 721-727 (1978)

7) Schümann, H.J. and Brodde, O.E.: Demonstration of $\alpha$-adrenoceptors in the rabbit heart by $\left[{ }^{3} \mathrm{H}\right]$-dehydroergocryptine binding. NaunynSchmiedeberg's Arch. Pharmacol. 308, 191-198 (1979)

8) Benfey, B.G.: Lack of relationship between myocardial cyclic AMP concentrations and Inotropic effects of sympathomimetic amines. Brit. J. Pharmacol. 43, 757-763 (1971)

9) Osnes, J.B. and Øye, I.: Relationship between cyclic AMP metabolism and inotropic response of perfused rat hearts to phenylephrine and other adrenergic amines. Adv. Cyclic Nucleotide Fes. 5, 415-433 (1975)

10) Schümann, H.J., Endoh, $M$. and Brodde, O.E.: The time course of the effects of $\beta$ - and $\alpha$ adrenoceptor stimulation by isoprenaline and methoxamine on the contractile force and CAMP level of the isolated rabbit papillary muscle. Naunyn-Schmiedeberg's Arch. Pharmacol. 289, 291-302 (1975)

11) Endoh, M., Brodde, O.E. and Schümann, H.J.:
Relationship between the level of CAMP and the contractile force under stimulation of $\alpha$ and $\beta$-adrenoceptors by phenylephrine in the isolated rabbit papillary muscle. NaunynSchmiedeberg's Arch. Pharmacol. 295, 109-115 (1976)

12) Osnes, J.B., Refsum, H., Skomedal, T. and $\emptyset y$, I.: Qualitative differences between $\alpha$-adrenergic and $\beta$-adrenergic inotropic effects in rat heart muscle. Acta pharmacol. toxicol. 42, 235-247 (1978)

13) Endoh, M. and Schümann, H.J.: Frequencydependence of the positive inotropic effect of methoxamine and naphazoline mediated by $a$-adrenoceptors in the isolated rabbit papillary muscle. Naunyn-Schmiedeberg's Arch. Pharmacol. 287, 377-389 (1975)

14) Ledda, F., Marchetti, P. and Mugelli, A.: Studies on the positive inotropic effect of phenylephrine: a comparison with isoprenaline. Brit. J. Pharmacol. 54, 83-90 (1975)

15) Mugelli, A., Ledda, F. and Mantelli, L.: Frequency dependence of the $\alpha$-adrenoceptormediated positive inotropic effect in guinea pig heart. Europ. J. Pharmacol. 36, 215-220 (1976)

16) Crout, J.R., Muskus, A.J. and Trendelenburg, U.: Effect of tyramine on isolated guinea-pig atria in relation to their noradrenaline stores. Brit. J. Pharmacol. 18, 600-611 (1962)

17) Endoh, M., Wagner, J. and Schümann, H.J.: Influence of temperature on the positive inotropic effects mediated by $\alpha$ - and $\beta$-adrenoceptors in the isolated rabbit papillary muscle. Naunyn-Schmiedeberg's Arch. Pharmacol. 287, 61-72 (1975)

18) Wagner, J. and Schümann, H.J.: Different mechanism underlying the stimulation of myocardial $\alpha$-and $\beta$-adrenoceptors. Life Sci. 24, 2045-2052 (1979)

19) Starke, K.: Regulation of noradrenaline release by presynaptic receptor systems. Rev. Physiol. Biochem. Pharmacol. 77, 1-124 (1977) 